\title{
«Abuelos de negra estirpe». Cuerpo, oralidad e identidad en María Teresa Ramírez, María Elcina Valencia y Nena Cantillo1
}

\author{
Estefanía Rodríguez Rozo \\ Licenciada en Español y Literatura de la Universidad del Quindío \\ Instituto Caro y Cuervo, Bogotá, Colombia \\ https://orcid.org/0000-0001-6508-483X \\ estefania.rodriguez@caroycuervo.gov.co \\ Guillermo Molina Morales \\ Doctor en Teoría de la Literatura por la Universidad de Zaragoza \\ Instituto Caro y Cuervo, Bogotá, Colombia \\ https://orcid.org/0000-0001-7484-3324 \\ guillermo.molina@caroycuervo.gov.co
}

\section{Resumen}

el término "poesía afrocolombiana» se refiere a un concepto en construcción para el que cada autor aporta su visión particular. En el presente artículo, establecemos un diálogo con tres autoras que comparten el lugar de enunciación de la mujer negra: María Teresa Ramírez (1944) en La noche de mi piel, María Elcina Valencia (1963) en Pentagrama de pasión y Nena Cantillo (1981) en Aquella noche con Winnie the Pooh. Para ello, trabajamos en torno a tres ejes: cuerpo, oralidad e identidad. Respecto al cuerpo, en los tres libros la mujer se asocia a la naturaleza, aunque varía mucho en la vinculación con el cuerpo masculino. La oralidad está muy presente en las tres obras, pero en diferentes formas: conexión con cantos ancestrales, con los sonidos de la naturaleza y con el habla coloquial de la urbe, respectivamente. En cuanto a la identidad, encontramos grandes diferencias entre la visión panafricanista de Ramírez, la ecosofía de Valencia y la apertura radical de Cantillo. En las conclusiones, discutimos la variedad de enfoques, las posibles causas y la riqueza que aportan para el concepto de «afrocolombianidad».

Palabras clave: Cuerpo; identidad; María Elcina Valencia; María Teresa Ramírez; Nena Cantillo; oralidad; poesía afrocolombiana.

\footnotetext{
1 Procedencia del artículo: Este artículo se deriva del proyecto de investigación "Poesía en movimiento", dirigido por Guillermo Molina Morales en el Instituto Caro y Cuervo.
}

Esta obra está bajo una Licencia Creative Commons Atribución-NoComercial Compartirlgual 4.0 Internacional. 


\section{"Grandparents of black lineage». Body, orality and identity in María Teresa Ramírez, María Elcina Valencia and Nena Cantillo}

\section{Abstract}

The term "Afro-Colombian literature" refers to a concept under construction for which each author contributes their particular vision. In this paper, we promote a dialogue with three authors who share the place of enunciation of the black woman: María Teresa Ramírez (1944) in La noche de mi piel, María Elcina Valencia (1963) in Pentagrama de pasión, and Nena Cantillo (1981) in Aquella noche con Winnie the Pooh. We choose three axes: body, orality and identity. Regarding the body, in the three books the woman is associated with nature, although it varies greatly in the relationship with the male body. Orality is very present in the three works, although in different ways: connection with ancestral songs, with the sounds of nature and with the colloquial speech of the city, respectively. In terms of identity, we find great differences between Ramírez's pan-Africanist vision, Valencia's ecosophy and Cantillo's radical openness. In the conclusions, we discuss the variety of approaches, the possible causes and the richness that they contribute to the concept of "Afro-Colombianity".

Keywords: Afro-Colombian literature; body; identity; María Elcina Valencia; María Teresa Ramírez; Nena Cantillo; orality.

Recibido: 17 de junio del 2020. Aprobado: 03 de julio del 2020

Artículo de reflexión https://doi.org/10.25100/poligramas.v0i51.10893

\section{¿Cómo citar este artículo en MLH? - How to quote this article in MLH?}

Rodríguez Rozo, Estefanía y Guillermo Molina Morales. "«Abuelos de negra estirpe». Cuerpo, oralidad e identidad en María Teresa Ramírez, María Elcina Valencia y Nena Cantillo"

Poligramas 51 (2020): n. pag. Web. Fecha de acceso (día, mes en mayúscula y abreviado, y año).

¿De qué hablamos cuando hablamos de «literatura afrocolombiana»? La pregunta se la hacía Silvia Valero en un artículo central para comprender un concepto muy relacionado con el 
contexto social y académico de las últimas décadas. Valero subrayaba el hecho de que "las representaciones ensayísticas o creativas bajo el rótulo de literatura afrocolombiana no son solo expresivas, sino constitutivas del mismo concepto" (27). En este sentido, Valero invitaba a superar las visiones deterministas que consideran "la diferencia étnica" como "un elemento inherente a todos los escritores negros" (29). En otras palabras, los rasgos que caracterizan a la literatura afrocolombiana se negocian dentro de esta misma literatura y, además, son heterogéneos según los distintos autores.

Así pues, en la presente investigación partimos de la consideración de que la tradición literaria afrocolombiana es un campo de posibilidades en continuo proceso de constitución, reinterpretación y cambio. Por otro lado, entendemos que no todas las autoras reconocidas con la etiqueta de "afrocolombianas» tienen, ni deben tener, el mismo tipo o grado de compromiso con dicha tradición. Es necesario evitar el determinismo y reconocer la libertad creadora. Para ello, necesitamos profundizar en los rasgos particulares de cada escritora, e incluso de cada libro publicado, en lugar de estudiar en bloque a las poetas con caracterizaciones fijadas de antemano.

Nos gustaría enfatizar que nuestro punto de partida no es el más habitual en los estudios sobre literatura afrocolombiana. Resulta más representativo, por ejemplo, un artículo como el de N'Gom sobre la antología ;Negras somos! de poetas afrocolombianas del Pacífico, en la que se incluye a dos de las autoras que estudiaremos. En dicho texto, el investigador se pregunta "qué significa o representa la experiencia de ser-mujer y negra" (121). Se trata, sin duda, de una pregunta pertinente. El problema surge cuando se pretende dar una respuesta única para las 21 autoras que conforman el corpus estudiado. La conclusión, en consecuencia, resulta excesivamente amplia y difusa. Así, las poetas buscarían "re-definir para la sociedad colombiana (...) los rasgos esenciales que conforman la identidad femenina negra" (132), pero no se precisa en qué consiste dicha redefinición, más allá de la denuncia de la definición anterior.

Para ser consecuentes con nuestra premisa, decidimos acotar el objeto de investigación a tres poetas afrocolombianas o, más concretamente, a tres libros escritos por autoras consideradas como poetas afrocolombianas. El proceso de selección se basó, inicialmente, en la antología de mujeres poetas de la Biblioteca de Literatura Afrocolombiana (colección que, según la ya citada Valero, fue quizás el mayor respaldo para el concepto de «literatura afrocolombiana»), a cargo de Guiomar y Ocampo. A partir de este listado, aplicamos dos 
criterios: por un lado, reflejar la diversidad de lugares de enunciación, al menos en lo referido a lugares de origen (Pacífico y Caribe) y a generaciones (una poeta nacida en los años 40, otra en los 60 y otra en los 80); por otro lado, basarnos en el reconocimiento previo que han tenido las poetas en el ámbito de la poesía afrocolombiana. En el caso de las poetas más jóvenes, al no existir todavía un canon consolidado, decidimos optar por una autora con posicionamientos distintos respecto a sus predecesoras, para así evitar redundancias.

Las dos poetas consolidadas son María Teresa Ramírez (1944) y María Elcina Valencia (1963). Junto con Mary Grueso, se trata de las dos autoras más citadas en el nuevo canon de poesía afrocolombiana escrita por mujeres. Las dos poetas han recibido el título honorífico de "almanegra", por parte del Museo Rayo, y han sido incluidas en la muy reciente Poemas y cantos: antología crítica de autoras afrodescendientes de América. El caso de Nena Cantillo (1981), como habíamos avanzado, es diferente, en el sentido de que su poesía no ha experimentado los mismos procesos de validación, ni tampoco parece apostar por similares principios poéticos.

María Teresa Ramírez Nieva (1944) resulta un buen ejemplo de cómo las reinterpretaciones personales pueden configurar la trayectoria literaria. Tras un primer libro escrito en lengua española (La noche de mi piel, 1988), Ramírez decide aprender la lengua palenquera y escribir en versiones bilingües (español y palenquero) el resto de su producción: Abalenga (2008). Flor de Palenque (2008) y Mabungú. Triunfo (dos tomos, en 2011 y 2016). El caso de Ramírez, que no tiene raíces en San Basilio de Palenque (ella procede del Pacífico), muestra la posibilidad de que una escritora redefina su identidad en un territorio distinto al esperado. Nuestro estudio se centrará en la primera obra, debido a la importancia de que los investigadores conozcan las lenguas usadas en el libro. La obra de Ramírez ha encontrado una amplia recepción académica y ha sido estudiada por autoras como Krakusin, Jaramillo y Osorio, con las que más tarde dialogaremos.

María Elcina Valencia Córdoba (1963) muestra un especial interés en la música (como estudiosa e intérprete) y en la danza, unas artes que influyen decisivamente en su forma de entender la poesía. También destaca su papel en la conservación y difusión del patrimonio inmaterial del Pacífico afrocolombiano. En cuanto a libros de versos, ha publicado títulos como Todos somos culpables (1993), Susurros de palmeras (2001), Analogías y anhelos (2008) y Pentagrama de pasión (2010). Para nuestro estudio, elegimos la última de estas obras, 
porque presenta una interesante fusión de los elementos que caracterizan la creación artística de Valencia y nos ofrece nuevos ángulos para abordar nuestras preguntas de investigación. María Elcina Valencia también ha sido estudiada por la crítica, aunque en menor medida: Jaramillo, Lawo-Sukam y Márceles Daconte son algunos de los académicos a los que nos referiremos.

Nena Cantillo Atuesta (1981) ha publicado, hasta la fecha, un único libro de poesía: Aquella noche con Winnie the Pooh (2011). Su vida y su obra están vinculadas a la ciudad de Cartagena a través de un estilo urbano y visceral. La poesía de Cantillo, que por primera vez se incluye en una investigación, muestra un tono provocador y humorístico que se distancia de los cánones tradicionales, incluyendo el reciente canon de poesía afrocolombiana. Sin duda, la fecha de nacimiento puede ser un factor importante para esta actitud, pero nuestro estudio busca estudiarla en su individualidad, no como representante de una generación.

Para nuestro estudio comparativo nos basaremos en tres ejes de análisis: cuerpo, oralidad e identidad. La elección de estos tres ejes surge tanto de la lectura del corpus crítico sobre el concepto de «literatura afrocolombiana» como de la revisión de los libros seleccionados. Se trata, en definitiva, de ejes centrales para entender las tres poéticas, así como las relaciones que pueden trazarse entre ellas. El primer eje nos permite analizar las concepciones del cuerpo: la común vinculación con la naturaleza y las diferentes maneras en que se entiende esta relación desde los lugares de enunciación de la mujer negra. El segundo eje se desplaza al cuerpo del poema y, en concreto, a la función de la oralidad en la configuración de las poéticas. En el tercer eje, estudiamos la construcción de la identidad en los tres poemarios, es decir, qué imaginarios utilizan los sujetos poéticos para definirse. En las conclusiones, articulamos los tres ejes de análisis para responder a la pregunta central de esta investigación: ¿cómo los libros estudiados han concebido el cuerpo, la oralidad y la identidad desde el lugar de enunciación de la mujer poeta afrocolombiana?

\section{«Besos que han florecido en mi carne negra»: poéticas del cuerpo}

Dentro de los aspectos más estudiados en la poesía contemporánea, especialmente en lo que se refiere a autoras afrodescendientes, el cuerpo ocupa un lugar destacado. Si entendemos la poesía como un espacio en el que fluyen y se negocian los significados, resulta esperable que el cuerpo negro, por su historia de sometimiento, adquiera un gran protagonismo. Estudios 
como los de Kumar y Aldana Mendoza nos ayudan a entender la importancia del cuerpo en la poesía escrita por afrodescendientes. Ambos autores coinciden en señalar que existe una tensión constante entre la cultura occidental dominante y las culturas "otras», que sienten la necesidad de reivindicarse a través de discursos de resistencia.

Por un lado, Kumar es tajante en señalar que el cuerpo ha sido un territorio violentado y que mediante la racialización se han posibilitado esquemas de sometimiento. En este contexto, según señala el propio Kumar, poetas como Nicolás Guillén han resignificado, a través del lenguaje, los imaginarios existentes sobre el cuerpo negro: "ahora son capaces de desafiar esos estereotipos y de reconstruir las imágenes adecuadas a sus verdades" (137). Por otro lado, Aldana Mendoza critica que los poetas afrocolombianos suelen situar a la mujer negra como objeto de deseo y que no existe una clara diferenciación entre la mujer negra y la mujer occidental. Las poetas afrocolombianas tendrían la tarea de reformular este esquema de subordinación. De hecho, nuestras poetas se insertan de alguna manera en esta línea de trabajo, ya que conceden mucha importancia al cuerpo como espacio de resignificación personal. Ahora bien, ¿cómo conciben el cuerpo en su obra?, ¿se trata de una concepción desafiante?, ¿cómo nos ayuda a entender el lugar de la mujer negra?

Para empezar, encontramos que en los tres casos resulta imprescindible la relación que el sujeto poético va tejiendo entre su cuerpo y la naturaleza. El término "ecosofía popular», propuesto por Oslender a partir de Arocha, puede servirnos para entender esta constante. Oslender destaca "la fuerte inscripción de lo ecológico en sistemas filosóficos locales" (210). Las comunidades afrocolombianas se relacionan con el entorno ecológico de manera horizontal, sin imponer un sistema de dominación. Esta forma de relación entre el cuerpo y el mundo natural en el que se inserta es fundamental en el imaginario de nuestras autoras. En concreto, lo encontraremos en dos vertientes: la primera es el agua y el cuerpo en movimiento; la segunda, el cuerpo como territorio. Por otro lado, existen diferencias entre las tres autoras en lo que se refiere a la relación con lo masculino.

María Teresa Ramírez se refiere al cuerpo en relación con el ideal panafricano que luego estudiaremos: "Tengo el dinga en mi sortija, / el mandinga en mis aretes, / el Yoruba en mi cintura/ y el Congo en mi canalete" (5). En cada verso, la poeta vincula una parte de su cuerpo (o un accesorio cercano a su cuerpo) con una cultura africana. Lo que ahora nos importa es que la conexión con los ancestros es posible a través del agua y el movimiento: "cuando voy 
rema que rema / por el río de la vida" (5). El río, por lo tanto, es el espacio necesario para este ritual de reconocimiento.

Algo similar ocurre en la poesía de Valencia. La poeta se conecta con el agua, aunque en su caso el elemento más trabajado es el mar. Como señala Lawo-Sukam, "el paisaje marino sirve (...) como herramienta para desarrollar la temática del amor y de la esperanza" (párr. 7). Lo vemos, por ejemplo, en los versos siguientes:

\author{
Soy recodo de una barca \\ perdida en el océano, \\ me besan tus aguas \\ y me envuelven \\ en sábanas blancas (21).
}

Al igual que en la poesía de Ramírez, el sujeto poético se concibe como una embarcación a merced de un río o un océano que la incluye. La diferencia es que Valencia imagina una vinculación erótica con un interlocutor individual, con el ser amado, en lugar de dialogar con la colectividad panafricana.

Por su parte, Cantillo muestra una análoga conexión con el agua en el poema «Acerca de no creer en príncipes», donde los elementos naturales y el cuerpo establecen una relación erótica muy estrecha, como lo muestra el verso "Nena ola atlántica" (74). Tres palabras que se refieren, respectivamente, al nombre de la autora, al elemento acuático y al espacio concreto del Caribe, en relación directa, sin conectores. Ahora bien, en Cantillo la relación se mantiene solamente en un plano físico y no necesariamente espiritual.

En cuanto a la concepción del cuerpo como territorio, en los tres poemarios está directamente vinculada a la presencia masculina, por lo que debemos estudiar ambas facetas de forma conjunta. En la poesía de Ramírez, encontramos versos tan significativos como los siguientes: "Mi cuerpo se convirtió / en mina, valle y / montaña" (19). El cuerpo, por lo tanto, se mimetiza con el territorio natural. En este mismo poema, al hombre se le atribuyen las funciones de «alpinista», «marinero» y "caminante», en una clara analogía erótica. Lo sorprendente es que esta analogía conlleva una visión del territorio como lugar de exploración en la que el hombre tiene el papel activo y dominante. Una visión similar se desprende de poemas como "Búscame», "Quiéreme» o "Déjame ser»: "Déjame ser / Sombra bienhechora (...), / eco de tu 
voz" (12). Así pues, el imaginario de Ramírez sobre el cuerpo femenino confirma lo que Kumar denominaba "las jerarquías actuales de poder" (31), al menos en lo que se refiere a los géneros. Este hecho contradice lecturas como las ya mencionadas de Aldana Mendoza y N'Gom, que conciben la poesía de las autoras afrocolombianas como un espacio necesario de subversión.

La poesía de Valencia se diferencia a la de Ramírez en cuanto que el sujeto femenino sí se siente autorizado para expresar su propio placer. Sin embargo, el imaginario de Valencia reitera las mismas claves que habíamos encontrado en Ramírez: el cuerpo como territorio natural que espera la llegada del hombre para darle sentido. Ya en el primer poema encontramos el esquema básico que se repetirá a lo largo del libro:

Tú la semilla...

Yo la tierra...

Una alianza por la vida (17).

La palabra "alianza» es importante. La alianza es lo que permitirá cumplir "a mi tierra sus anhelos de cosecha" (54), como dice en otro poema. Son versos que posiblemente no compartiría un buen número de mujeres de nuestro tiempo, por cuanto subrayan el papel de la mujer como reproductora en rol pasivo. Sin embargo, estos poemas se insertan en una visión ecosófica donde los humanos encuentran una armonía en la repetición de los ciclos de la naturaleza.

La ruptura con el imaginario tradicional sobre el cuerpo de la mujer solamente la encontramos en la poesía de Cantillo. La más joven de las tres poetas continúa relacionando cuerpo y naturaleza: "Hay tres besos que han florecido en mi carne negra" (59), dice en una pieza que también hablará del amamantamiento. Sin embargo, en la mayoría de los poemas se percibe un deseo de cambio, una relación menos armónica con el hombre y la naturaleza:

Por ser hiedra y verdolaga en tu sendero

por asesinar tu resistencia

Y animarte a forjarme unas alas invencibles (54). 
Lejos de asumir una posición subordinada, el sujeto femenino interpela a su par masculino para que le otorgue unas "alas invencibles». Con este símbolo de libertad y de fuerza, se pretende superar la posición subordinada y terrestre de la «hiedra» y la «verdolaga».

Otro elemento diferenciador en Cantillo es que el erotismo ya no aparece ligado a la reproducción, como vimos en Valencia, sino que rompe con toda idea de trascendencia y prefiere centrarse en sensaciones físicas como el placer y el dolor. En este contexto, el cuerpo de la mujer ya no se relaciona con la espera. Cuando el hombre llega, la mujer puede ponerlo en cuestión, e incluso reírse de sus pretensiones:

El señor arequipito me acribilla a poemas diabéticos, se me viene de golpe como un bicho del planeta feliz (...).

Pobre tipo tratando de entrar en mí, tan oscura de tez y caminos (29).

En el primero de los versos, el uso del diminutivo y del esdrújulo final supone una parodia no solamente hacia el actuar del hombre, sino también hacia los tópicos románticos, incluyendo la poesía tradicional, demasiado cargada de dulzura. El «príncipe» del poema queda ridiculizado por su lenguaje y por su caracterización: es un hombre viejo, torpe, drogadicto, etc. Importa subrayar que la oscuridad de la tez se asocia a la oscuridad de los caminos: el cuerpo de la mujer negra es ahora un lugar de enunciación que se abre a lo indefinido.

Concluimos este apartado resaltando que en las tres autoras es fundamental la visión ecosófica que vincula el cuerpo con los elementos naturales, tal y como lo anticipaba Oslender. Este rasgo sería el que caracterizaría la concepción del cuerpo en las obras estudiadas, así como el vínculo más claro con una posible tradición afrocolombiana. Ahora bien, dentro de este marco común encontramos importantes diferencias, sobre todo en lo que se refiere a la relación erótica con el hombre. La poesía de Ramírez y de Valencia no parece rebelarse contra el rol pasivo de la mujer, sino que, por el contrario, lo sedimenta en la relación con la naturaleza. Este hecho no debe interpretarse de manera negativa: al fin de cuentas, supone la continuación de imaginarios ancestrales. En la poesía de Cantillo, en cambio, sí encontramos una ruptura respecto a estos imaginarios, lo que podemos atribuir a distintas variables, como veremos en las conclusiones. 


\section{«¿H voj quién te trujo?»: el componente oral}

Las tres obras que estudiamos han sido escritas y publicadas en forma de libros. Sin embargo, en las tres está muy presente la oralidad. Se trata, en mayor o menor medida, de textos híbridos en los que el componente oral sirve como enlace a una tradición colectiva. Por otro lado, recordemos que el tránsito de la oralidad a la escritura "forma parte integral de la evolución moderna de la conciencia hacia una mayor interiorización y una mayor apertura" (Ong 173). En otras palabras, la escritura posibilita que la tradición sea reinterpretada por la individualidad de cada poeta.

Es habitual señalar el nexo que une a la literatura afrocolombiana y a la oralidad ancestral, en oposición a una oralidad occidental y, sobre todo, al mundo de la literatura escrita. Ahora bien, Valero nos advierte contra "el error de abstraer reductivamente a dos miembros complejos, al mismo tiempo que los presenta como intocados uno con otros" (32). De hecho, la poesía que analizamos solo puede entenderse desde la hibridación de ambos miembros: ni se trata de cantos orales transcritos en libro, ni tampoco de poemas cerrados que inviten a una lectura callada. Tenemos que movernos, en definitiva, a lo largo de las posiciones intermedias de este espectro.

Ciertamente, nos inclinaríamos hacia el polo del canto si analizáramos, en lugar de los textos escritos, la puesta en escena de los versos. Muchas poetas afrocolombianas, entre las que se cuentan Ramírez y Valencia, son conocidas por recitales en los que cobran gran importancia elementos como la voz, los sonidos y los movimientos del cuerpo. Además, los textos escritos pueden tener variaciones en el momento de la actuación. Sin duda, podría estudiarse la obra de nuestras poetas con base en los recitales. Ahora bien, como afirma Pacheco, la oralidad "va mucho más allá de la exclusividad o el predominio de un medio comunicacional sobre otro" y es capaz de incidir "en el desarrollo de concepciones del mundo y sistemas de valores, así como de particulares productos culturales" (60). Es en este sentido que podemos estudiarla en los textos escritos, en donde la oralidad deja huellas tanto culturales como formales.

La obra de Ramírez es la que más claramente busca vincularse con la ancestría. En concreto, busca el enraizamiento con una gran tradición panafricana que, en principio, era de naturaleza oral. Vamos a encontrar la vinculación en los referentes, en las imágenes y en la propia semántica de los versos, como lo veremos en el apartado siguiente. Lo que ahora nos 
interesa subrayar es que este componente tradicional configura también la forma de los poemas. Betty Osorio apunta que la poeta "recoge el eco poderoso y espiritual de estos rituales y lo hace circular por fuera del espacio académico para convertirlos en vivencia" (párr. 34). Esta vivencia, lógicamente, aparece de forma más intensa en los mencionados recitales. La lengua palenquera, además, se convierte en una lengua ritual. Ahora bien, ¿cómo es posible vincularse a la tradición en un libro escrito en español?

Algunas de las herramientas que utiliza Ramírez en su poesía han sido señaladas por Krakusin. La investigadora nombra el ritmo del tambor, la anáfora, la jitanjáfora, la proximidad a géneros orales como la canción de cuna y el planto, y el uso de "cándidas expresiones propias de las almas sencillas" (202). Se trata de elementos fundamentales para entender cómo un poema escrito puede vincularse con la oralidad. Daremos ahora un paso más. Además de lo anterior, creemos que es fundamental reconocer la importancia de la tradición de poesía afroamericana en la configuración de la obra de Ramírez. Es decir, la autora acude a la mediación de la poesía escrita de Latinoamérica para lograr la conexión con la oralidad africana.

En concreto, son explícitas las referencias a dos poetas mayores: Candelario Obeso y Nicolás Guillén. De Obeso (poeta decimonónico del Caribe colombiano) recoge la escritura fonética, en especial el uso de la grafía «j» en lugar de la «S» normativa y de la «r» en lugar de la "d» intervocálica; el referente del río y de la navegación; y algunas expresiones distintivas del momposino, como "remá, remá" (p. 5). De Guillén (poeta cubano representante del «negrismo» de la primera mitad del siglo XX) toma estructuras rítmicas, expresiones icónicas como "Sensemayá» o "Congo Solongo" y descripciones para personas, ya convertidos en personajes, como Sabás Mandinga.

Así pues, los poemas de Ramírez enriquecen su lectura con una multiplicidad de huellas que nos remiten, de diversas maneras, a los ancestros. Tomemos un poema como "Anonarara»:

Me siento anonarara

Ejtoi, totarmente sin ánimo,

como ricen que vivía

un tar Garrick,

pualla por laj Inglaterraj,

ricen que tenía rinero,

libros, casas y re toro (...). 
Laj lágrimaj se me rueran
como en er río la canoa (2).

Sin negar una primera asociación (siempre problemática) entre el sujeto poético y la poeta, estos versos se conectan de diversas maneras con la colectividad. La conexión se realiza a través de marcas de oralidad en la forma y en la visión de mundo. En cuanto a la forma, la escritura fonética nos remite al habla de una comunidad, pero también a la poesía de Obeso. La estrofa de verso menor, aunque irregular en este caso, nos remite a la poesía popular cantada. En la visión de mundo, donde un sujeto muestra su sentimentalidad y su posición subordinada, sería imposible discernir qué tanto hay de cultura popular y qué tanto de tradición letrada (por ejemplo, a través de Guillén). De forma análoga, en la referencia al actor inglés David Garrick (1717 - 1779), se hibrida la cultura letrada extranjera (el actor fue conocido por interpretar obras de Shakespeare), la cultura letrada latinoamericana popularizante (el poeta mexicano Juan de Dios Peza escribió un conocido poema sobre él) y la cultura popular oral afrocolombiana.

En el caso de Valencia, el componente oral es todavía más obvio, si tenemos en cuenta la vinculación directa de la poeta con el canto y el baile, en la tradición del Pacífico colombiano. Lawo-Sukar destaca la imbricación que realiza Valencia entre palabra, música y danza. En conjunto, "el objetivo principal (...) es el rescate del folclor afrocolombiano que constituye el alma de la identidad negra" (párr. 8). De forma similar a Ramírez, Valencia "para expresar el contexto secular de la cultura, usa la repetición, la onomatopeya y la jitanjáfora" (párr. 8). Las citas de Lawo-Sukar nos ayudan a comprobar dos cuestiones que ya habíamos mencionado: la importancia de la puesta en escena y el uso de elementos formales en la escritura para facilitar la interpretación oral posterior.

Adicionalmente, en el libro que hemos seleccionado aparecen dos elementos novedosos. El primero nos lo señala el propio título de la obra: Pentagrama de pasión. El pentagrama es una herramienta de origen occidental para la escritura de la música. En este sentido, la obra de Valencia construye un nuevo ángulo para entender la hibridación entre lo escrito y lo oral. Veámoslo con algunos versos del poema titulado, precisamente, "Pentagrama de pasión»: 
Arriba de Sol,

soy el espacio de tu corchea

soy tu Fa,

La Do Mi (...).

Vuelve a mí en ritornello

y salpícame tu estacato.

Prolóngame con tu calderón

para sonarte eternamente

al murmullo de sinfonías

que inventas cada tarde (89).

En estos versos, encontramos un juego con la música que, en cierta medida, contradice lo que esperaríamos. El pentagrama y los demás elementos de notación no son, en este caso, simples medios para la posible transcripción de una música tradicional. Por el contrario, la propia forma de escritura se convierte en el motivo sobre el que establecer la analogía erótica. Para entender cabalmente la pieza, es necesario imaginar el pentagrama como un espacio en donde juegan corporalmente las distintas notas. De forma coherente, el poema explora las posibilidades de la materia gráfica del poema, a través de la disposición de las palabras sobre la página en blanco. En definitiva, los poemas de Pentagrama de pasión se inclinan claramente hacia el lado de la escritura, de la imaginación espacial y de la materia gráfica, por encima de la propia musicalidad, ritmo o juego con la materia sonora.

Por otro lado, uno de los versos citados nos sirve para introducir la otra peculiaridad que encontramos en el libro de Valencia. Se trata del «murmullo de sinfonías». En el contexto del poema, este «murmullo» se distancia de la jerga musical anteriormente empleada: remite a otro tipo de sonidos. En la poesía de Valencia encontramos un marcado énfasis por mostrar la sonoridad de los elementos naturales (el viento, el agua, etc.), lo que creemos ligado a la visión ecosófica a la que nos referíamos anteriormente. Nos referimos a versos como "tempestuoso océano de la aurora" (24), "se expande como espumas sobre el río" (27) u "olas diminutas / arriman silenciosas a mi orilla" (53). En estos casos, la sonoridad de la naturaleza queda reforzada por el trabajo con las aliteraciones de los versos. 
En la poesía de Cantillo, al igual que en Ramírez y en Valencia, se muestra un intento de conexión con los antepasados. Sin embargo, en este caso el diálogo se establece de manera más inmediata, a través de los padres del sujeto poético. Por ejemplo, en «Presente del 12 de mayo» se plantea un diálogo intergeneracional con reconocimiento de la "carne negra»:

Memoricé el olor a humo de tus polleras mama Sole y guardé para esta hora tu voz de bullerengue guiando el caderaje festivo Hace algún tiempo la mama sonreía y limpiaba la gota leche de aquellos labios ya saciados "Crecerás y serás de bien como tu papa"Así decía (59).

Este es uno de los pocos poemas del libro en el que aparece explícitamente mencionada la tradición afrocolombiana, con referentes como el bullerengue. Sin embargo, a diferencia de las poetas anteriores, la conexión ancestral no se realiza a través de versos cercanos al canto ritual, sino en una estructura narrativa que gira en torno a una escena familiar. Estos elementos (la individualidad de los sujetos y la estructura narrativa) caracterizan de forma decisiva al libro estudiado.

Dichos elementos se desarrollan en poemas que, por lo general, tienen al barrio como escenario y al habla urbana como interlocutor principal. El habla aparece marcada desde la tipografía, ya que las distintas voces se reproducen en letra cursiva. De esta manera, se genera una suerte de polifonía en la que participan distintos personajes del libro en diálogo con el sujeto poético: desde vecinos anónimos del barrio hasta escritores como Raúl Gómez Jattin. Además, el uso de expresiones populares (refranes, canciones, interjecciones, etc.) aporta al libro una dimensión colectiva. Veamos cómo opera esta polifonía a partir de un fragmento del poema «Beto», que se refiere a un joven vendedor de lotería en la periferia de Cartagena:

Cheíto le da unas cuantas instrucciones a Beto. Todos parten al lugar acordado.

- Mi compae no le dé mente que la vuelta es breve.

"la vuelta es breve, la vuelta es breve, hoy comeremos carne"

Anochece. Se produce un atraco en la tienda de un barrio

vecino, los ladrones emprenden la huida. 


\begin{abstract}
El tendero paisa sale a mitad de la calle enloquecido, apunta, dispara y cae un ladrón, uno de los chicos en la carrera ha desparramado billetes de lotería que ahora la brisa arrastra... (51).
\end{abstract}

Encontramos aquí una forma de componer poesía muy diferente a la estudiada en las poetas anteriores. El poema desarrolla la narración de un atraco de una manera que se acerca más al cine que al canto. En cursiva, encontramos una frase que respeta las peculiaridades del habla coloquial urbana, con expresiones como «darle mente» o elisiones fonéticas propias de la costa ("compae»). Entre comillas, una expresión popular que funciona como un coro colectivo. Nótese, además, cómo en el último de los versos transcritos aparece un lirismo inesperado en el contexto de la narración. Es este verso, además, el que escapa de la mera descripción de hechos para aportarnos una reflexión sobre los mismos: la vida en el barrio como billetes de lotería que la brisa arrastra.

En otros poemas, como "Ejercicios de escritura para no cometer un crimen", el componente narrativo se desarrolla a través de la mera reproducción de diálogos y monólogos interiores: "Ésa es mundial! Chiquita, me está hablando al teléfono, me / llamó (Milagro!) y de pronto se dirige a otra: / - Eh tú! Adónde vas?' (42). En el ejemplo, la polifonía llega hasta las últimas consecuencias: resulta difícil identificar quién está hablando o pensando, e incluso dónde comienzan y terminan las frases. La oralidad urbana, por lo tanto, es fundamental en la composición del libro de Cantillo: se vincula a un tipo de colectividad diferente a la ancestral y, en consecuencia, muestra rasgos diferenciados (por ejemplo, la inclusión de la interioridad).

Otra novedad importante, que sirve para apuntalar lo anterior, es el uso de la cultura de masas, ya desde el título, con el referente de «Winnie the Pooh». Al fin de cuentas, para un sujeto moderno que crece en la ciudad, los referentes televisivos son parte importante de su educación sentimental. De hecho, los cuentos populares con los que trabaja la autora ya no se limitan al folclor afrocolombiano, sino que pertenecen a una cultura popular internacional popularizada por los medios de comunicación de masas. En concreto, el libro parodia los cuentos de princesas Disney y, en consecuencia, su lenguaje. Por ejemplo, «Relato de una chica que no creía en Príncipes azules", que comienza con el verso "Pero él siguió insistiendo en que ella era una rosa". Existe aquí una voluntad de rebelarse contra los estereotipos, aspecto que 
profundizaremos en el siguiente apartado. Lo que por el momento nos interesa subrayar es el cambio en los referentes que definen la colectividad.

En este breve recorrido, hemos encontrado formas de oralidad muy distintas, que también corresponden a distintos interlocutores colectivos. Ramírez se vincula con los cantos ancestrales a través de la tradición escrita afroamericana. Valencia, en la obra estudiada, prefiere referirse a los sonidos de la naturaleza. Finalmente, la oralidad en la poesía de Cantillo se basa en el habla coloquial de una ciudad identificable como Cartagena de Indias. A continuación, estudiaremos cómo estas diferencias se articulan en distintas percepciones sobre la identidad.

\section{«No indagues por quién soy»: el problema de la identidad}

La identidad es un constructo en continuo movimiento que cada persona reinterpreta de forma diversa. En este sentido, no sería apropiado buscar rasgos de «afrocolombianidad» en nuestras poetas, sino, más bien, estudiar cómo cada una de las autoras concibe la identidad individual o colectiva. En esta concepción, puede existir un mayor o menor énfasis en la etnia o en el género, sin que pueda interpretarse la predilección por otros referentes como una forma de escapismo. La poesía, al fin de cuentas, es un espacio para negociar la identidad de manera creadora.

Encontramos que cada uno de los libros estudiados concibe la identidad de una manera distinta. Ramírez se basa en la reconexión panafricanista con los ancestros, Valencia se define en relación con la naturaleza, mientras que Cantillo enfatiza las posibilidades de la multiplicidad $y$, en este sentido, evita una definición cerrada. Estas visiones generales se concretan en una serie de imágenes y referentes que analizaremos a continuación.

En La noche de mi piel, de María Teresa Ramírez, la identidad está ligada, desde el primer poema, a los "abuelos de negra estirpe" (1). Ramírez busca conectarse con lo africano desde una perspectiva muy amplia, incluso mítica, en lugar de limitarse a las coordenadas concretas desde las que escribe. En este sentido, no hay referencias concretas a su Pacífico natal, sino a lugares de África, muy distantes entre sí. En «Mi potrillo», por ejemplo, yuxtapone ríos del Congo, selvas de Kenia y arenas del Sahara. La identidad, por lo tanto, se construye desde una memoria deseada de los orígenes, que puede definirse como un imaginario panafricanista. Jaramillo (en referencia a las poetas Ramírez, Grueso y Valencia) ha estudiado este imaginario al hablar de la "imagen idealizada de África como una madre y raíz nutricia", lo que genera "un tono nostálgico por esa tierra ancestral que evocan y que quieren recuperar a través de su creación 
lírica" (párr. 1). No cabe duda de que este empeño es fundamental para entender la obra de Ramírez.

La visión panafricana se completa en los poemas con la referencia a otros grupos marginados. Nos referimos a poemas como «Pan auténtico», donde también se ofrece una visión idealizada (y un tanto maniquea), en este caso de la pobreza. En las escenas del poema, los ricos no son capaces de disfrutar el pan francés, mientras que "el pan en la casa del obrero (...) / se reparte proporcionalmente" (18), no solo entre los miembros de la familia, sino incluso con los vecinos del barrio. Ambas figuras idealizadas (la del negro y la del pobre) se dan la mano en el poema "La abuela negra», donde se dignifica "el morral proletario" (20) de la protagonista.

Así pues, Ramírez busca la identidad a través de la conexión mitificada con los ancestros africanos y con los pobres. Ahora bien, después de algunos poemas en este sentido, la tónica del poemario se caracteriza, sin lugar a dudas, por el tema amoroso. El amor se entiende en el libro en un sentido tradicionalmente romántico. Es decir, se trata de un constructo cultural que pretende ser naturalizado: "Quiéreme por el amor en si [sic] mismo / con sus leyes naturales" (16). En este sentido, el sujeto poético parece desprenderse de toda identidad individual. Como dicen los propios versos: "El amor está por encima / de mi yo" (24). Vimos anteriormente que en este imaginario resulta fundamental para el discurso ecosófico por su conexión con el cuerpo como espacio natural en espera del hombre.

Ambos tipos de poemas, los que tratan sobre los orígenes colectivos y sobre el amor, convergen en mostrar una identidad dependiente, sin que este hecho deba ser pensado de manera peyorativa. El sujeto no se concibe como individuo, sino con relación a otros (los ancestros) o a otro (el amado). Así, la protagonista se concibe a partir de los dos términos "amante-esposa», que dan título al poema. En "Yo soy la otra», la amante protesta contra las mentiras del amado, que tiene esposa e hijos, a pesar de lo cual el sujeto femenino insiste en la imagen de un amor "que viene del alma" (22) y la domina. De forma análoga, en el ya citado poema "La abuela negra», la protagonista, aunque "aureada en su dignidad" (20), es definida solamente por su relación con los nietos. De nuevo, encontramos aquí una visión armónica de las relaciones entre los individuos, donde persisten y se naturalizan los roles culturales tradicionales. 
Este mismo deseo de fusión con el ser amado se muestra en Pentagrama de pasión, de María Elcina Valencia. La diferencia de este poemario es que no encontramos el tema de los ancestros ni alguna otra forma de filiación identitaria. Sin embargo, estos rasgos sí aparecen en poemarios anteriores. Jaramillo afirma que la autora "indaga en sus orígenes, usa el lenguaje de sus abuelos, nomina con orgullo los productos de su tierra, alaba los bailes típicos del Pacífico" (párr. 16). Este arraigo con lo afrocolombiano, y, en concreto, con el territorio del Pacífico, ha sido también señalado por críticos como Lawo-Sukam y Márceles Daconte. En este sentido, debemos entender que el libro estudiado ahonda en el erotismo y deja provisionalmente de lado otras problemáticas, sin que esto suponga obviarlas en el conjunto de su obra.

En Pentagrama de pasión encontramos una hibridación entre la identidad individual y la naturaleza, es decir, una "consustanciación" con el entorno a través de la ecosofía. Este tipo de relación permea la producción amorosa que caracteriza al poemario. Como vimos en el apartado dedicado al cuerpo, el sujeto poético asume el papel pasivo que tradicionalmente se relaciona con las mujeres, así como la función reproductiva del sexo. Veámoslo en los siguientes versos:

Invádeme... habítame,

vuélveme territorio,

clava en mi tierra

semillas nuevemesinas (18).

Encontramos aquí el anhelo de la posesión, con un lenguaje bélico donde el sujeto se atribuye el papel de conquistada anhelante. La mujer se define por su capacidad para engendrar hijos, para lo cual necesita la «invasión» de un hombre. Un hombre que, sin lugar a dudas, se asocia al imaginario masculino del semental, como sucede en un poema posterior: "Yo... / Desnuda... / Espero que me cubras" (21). El verbo "cubrir» enlaza el acto sexual humano con el de los animales, en una nueva conexión con el mundo natural.

En definitiva, la poesía de Valencia, como la de Ramírez, presenta un sujeto poético que adquiere identidad a través del hombre amado. El caso de Nena Cantillo es muy diferente. Es cierto que el amor tiene cierta relevancia en la obra, pero aquí encontramos una figura de mujer distinta, empoderada, capaz de llevar la iniciativa e, incluso, de usar los estereotipos en su favor. Así, en el poema "Princesa retorcida» se niega al hombre la posibilidad de «imaginarme idónea», 
es decir, de intentar encajonar a la protagonista en un esquema tradicional. De hecho, el sujeto femenino busca "estafar / hombres incautos" (18) a través de la apariencia de "cándida muñequita mulata", tras la cual se oculta un "delirio de hiena" (18). El sujeto no se identifica con categorías como la de "muñequita mulata», sino que utiliza esta imagen prefijada para engañar, en lo que podemos reconocer la figura tradicional del trickster.

En este contexto, ¿en qué consistiría la identidad del sujeto? Lo vemos en los siguientes versos, que proceden del poema ya citado:

No indagues por quien soy

Soy muchas y ninguna (...)

No pretendas imaginarme idónea (19).

Lo único cierto, por lo tanto, es la ausencia de verdades. Una identidad completamente fluida, que se niega a ser definida, es decir, limitada. Lo único que parece tener claro es la denuncia de los modelos anteriores, para lo que la autora subvierte relatos fijos, en especial el de los cuentos de princesas: "Los grandes autores nos mintieron" (20), señala. Lo mismo sucede con el discurso poético tradicional en el poema homónimo del libro, "Aquella noche con Winnie Pooh", donde el hombre "sigue recitándome poemas / que le brotan en el momento, Nomititos dulces", a lo que sigue una parodia de expresiones como "nena bañada de luna" (28). En este sentido, Cantillo parece desconfiar de los discursos amorosos y lugares comunes, a diferencia de Ramírez y Valencia, para quienes nombrar es un acto de certidumbre.

Con todo, encontramos en Cantillo una conexión con el imaginario afrocolombiano a través de los oficios. Como señala Aldana Mendoza, el reconocimiento de los oficios que desempeñan las mujeres como "maestras, brujas, cocineras, poetas, narradoras, actrices" se refiere también a las madres y las abuelas (80). En estas labores existe un gran potencial para redefinir los elementos específicos de la poesía afrocolombiana. En este sentido, Cantillo, quien aparentemente es la más alejada del discurso tradicional entre las tres poetas, recuerda en su poema "Presente del 12 de mayo» la imagen de la mujer que cuida a sus hijos. "Mama Sole», se dibuja no solo por su rol maternal, sino por otros elementos como el "olor a humo» en sus "polleras», que nos indica el oficio de la cocina. Adicionalmente, en los versos "la ropa que tú / consumida me lavabas, / sangre de otros en tu batea de piedra" (59) aparece el oficio de la 
lavandería a través de un objeto tradicional de los pueblos ancestrales: la "batea de piedra». Por último, otro oficio que desarrolla «Mama Sole» es el del canto: "te imagino cantándome tu bantú 20 años atrás". Así pues, a través de los oficios, el sujeto entronca con un legado ancestral, si bien parece más ligado al pasado (el recuerdo de la madre) que al presente personal.

\section{Conclusiones}

Al inicio de este artículo, nos referíamos a la «literatura afrocolombiana» como un concepto en proceso de construcción. Algunos de los rasgos analizados coinciden en las tres autoras estudiadas y, en este sentido, pueden formar parte de un bagaje compartido. Nos referimos, en concreto, a la vinculación del cuerpo de la mujer con la naturaleza, a las huellas formales y culturales de la oralidad en los poemas y a la mención de los ancestros negros como parte de la identidad de los sujetos. Sin embargo, las diferencias han sido quizás más notables, sobre todo por cuanto contradicen parcialmente lecturas anteriores. En este sentido, hemos encontrado un rol pasivo de la mujer en la poesía de Ramírez y Valencia, tipos de oralidad muy diferentes en los tres libros, así como una identidad abierta y múltiple en la obra de Cantillo. Estas características muestran la saludable heterogeneidad existente bajo la categoría de "poesía afrocolombiana».

Por otro lado, hemos hallado importantes afinidades en las obras de Ramírez y de Valencia en cuanto a la concepción del cuerpo, la oralidad y la búsqueda de arraigo en la ancestría africana. Se trata de dos autoras centrales en el canon de la poesía afrocolombiana actual. Si descartamos el esencialismo (esto es, la pre-existencia de unos rasgos que las autoras reflejan en sus obras de manera mecánica), podemos arriesgar dos hipótesis, compatibles entre sí, para entender las coincidencias y el lugar en el canon: por un lado, la inclusión en el canon puede estar influida por el hecho de que la obra de las autoras coincide con lo que los críticos esperan de una poeta afrocolombiana; por otro lado, las propias poetas están creando el canon al insertarse en una determinada lectura de la tradición anterior.

El caso de Nena Cantillo es importante para mostrarnos que las autoras reconocidas dentro de la categoría de "poesía afrocolombiana" pueden tomar rumbos distintos. Aunque existe una análoga vinculación con la naturaleza, la obra de Cantillo muestra diferencias esenciales respecto a la de Ramírez y Valencia. Nos interesa destacar la elección de una identidad múltiple y abierta que, por un lado, parece responder mejor a las exigencias de la 
sociedad moderna o posmoderna; pero que, por otro lado, dificulta establecer una clara vinculación con la tradición afrocolombiana. Esta identidad «líquida» puede explicarse por múltiples motivos: el cambio generacional, la cultura urbana, la percepción que la poeta tiene de sí misma o una simple opción personal dentro de la libertad creadora.

Una fortaleza del presente estudio ha sido la oportunidad de profundizar en un corpus limitado a tres obras, ya que nos ha permitido atender a sus particularidades. Esta fortaleza, sin embargo, se convierte en una limitación en el momento de extrapolar conclusiones o de establecer patrones para la "poesía afrocolombiana». Es necesario seguir indagando con un corpus más amplio en las problemáticas planteadas. Estudios futuros podrían avanzar en la respuesta a algunas de las preguntas que dejamos aquí planteadas, como la relación entre el canon y ciertas opciones estéticas, o la multiplicidad de posibilidades dentro del campo literario afrocolombiano. Una hipótesis plausible sería pensar en la poesía de Ramírez y Valencia como un momento fundacional que establece una tradición propia y un canon presente. Desde esta perspectiva, las poetas afrocolombianas del futuro podrían optar por la repetición de patrones tradicionales (lo que no debe ser visto como una opción menor en el contexto de una cultura tradicional) o por la puesta en movimiento de este canon para buscar nuevos horizontes.

Por otro lado, la crítica literaria de los próximos años podría arriesgarse a definir criterios de calidad literaria que vayan más allá de la representatividad y de la importancia cultural que tiene la obra de nuestras poetas. Se trata de una cuestión compleja y muy controvertida, pero creemos que Valero tiene razón al negarse a tratar las obras de las poetas afrocolombianas como un simple documento sociológico. Esto no significa que las obras de nuestras poetas deban enfrentarse a los criterios de valoración de la Modernidad occidental, que se basan en la tradición de la ruptura. Nuestra propuesta sería respetar la heterogeneidad cultural y reconocer dos líneas de trabajo relacionadas pero diferentes: la poesía popular, en la que se insertaría Ramírez y Valencia (aunque con la hibridez propia de un texto escrito), y la poesía letrada, que parece más adecuada para entender la obra de Cantillo. En realidad, todas las poetas, por el simple hecho de escribir libros, forman parte de la cultura letrada, pero queremos señalar que existen diversos grados de vinculación con la tradición popular y con la tradición moderna.

Al inicio de este artículo, nos preguntábamos cómo los libros estudiados han concebido el cuerpo, la oralidad y la identidad desde el lugar de enunciación de la mujer poeta afrocolombiana. La única respuesta conjunta es que los libros conciben estos elementos desde 
una sana diversidad de opciones. Al hilo de lo que escribimos en el párrafo anterior, posiblemente suceda que, en el momento de crear poemas, tan relevante es el lugar de enunciación como la tradición en la que cada autora busca libremente insertarse. Ninguna poeta está limitada a mirar, pensar o escribir de determinada manera por haber nacido en un contexto de raigambre ancestral. Al fin de cuentas, la poesía es un espacio de negociación y de libertad que no se deja encadenar fácilmente.

\section{Referencias}

Aldana-Mendoza, María. "Las mujeres en la poesía afrocolombiana". Lectores dentro y fuera de los textos literarios: Convergencias 2011. Ed. Liliana Galindo Orrego. Bogotá: Ediciones Uniandes, 2013. 67-85. Impreso.

Cantillo Atuesta, Nena. Aquella Noche Con Winnie the Pooh. Mompox: Ediciones Pluma de Mompox, 2011. Impreso.

Cuesta Escobar, Guiomar y Alfredo Ocampo Zamorano, eds. Antología de mujeres poetas afrocolombianas. Bogotá: Ministerio de Cultura, 2010. Digital.

Jaramillo, María Mercedes. "Los abuelos como arcas de la memoria en los versos de las Almanegras del litoral Pacífico colombiano". Poemas y cantos: antología crítica de autoras afrodescendientes de América Latina. Biblioteca Digital de la Biblioteca Nacional de Colombia. Web. <https://bibliotecanacional.gov.co/es-co/colecciones/bibliotecadigital/poemas-y-cantos/Paginas/00-home.html>

Krakusin, Margarita. "Cuerpo y texto: el espacio femenino en la cultura afrocolombiana en María Teresa Ramírez, Mary Grueso Romero, Edelma Zapata Pérez y Amalia Lú Posso Figueroa". Chambacú, la historia la escribes tú: ensayos sobre cultura afrocolombiana. Ed. Lucía Ortiz. Madrid: Iberoamericana, 2007. 197-216. Impreso.

Kumar, Ashwani. "La representación de los cuerpos humanos como sitios de discriminación y desafío en la poesía afro-caribeña y dalit: un estudio comparado". Actas del I/l Congreso Ibero-Asiático de Hispanistas. Eds. Mariela Insúa, Vibha Maurya y Minni Sawhney. Pamplona: Universidad de Navarra, 2015. Digital.

Lawo-Sukam, Alain. "María Elcina Valencia Córdoba: cantante del pueblo afrocolombiano". Poemas y cantos: antología crítica de autoras afrodescendientes de América Latina. Biblioteca Digital de la Biblioteca Nacional de Colombia. Web. 
$<$ https://bibliotecanacional.gov.co/es-co/colecciones/biblioteca-digital/poemas-ycantos/Paginas/00-home.html>

Márceles Daconte, Eduardo. "Poesía de mujeres afrocolombianas del Pacífico: Una visión desde el Caribe". Poemas y cantos: antología crítica de autoras afrodescendientes de América Latina. Biblioteca Digital de la Biblioteca Nacional de Colombia. Web. $<$ https://bibliotecanacional.gov.co/es-co/colecciones/biblioteca-digital/poemas-ycantos/Paginas/00-home.html>

N'Gom, Mbare. "Representaciones de la otredad: experiencia femenina e identidad en jNegras somos!". Cuadernos de Literatura. 19.38. 2015: 119-136. Digital.

Ong, Walter. Oralidad y escritura. Tecnologías de la palabra. México: Fondo de Cultura Económica, 1994. Impreso.

Oslender, Ulrich. "Discursos ocultos de resistencia: tradición oral y cultura política en comunidades negras de la costa pacífica colombiana". Revista Colombiana de Antropología. 39. 2003: 203-235. Digital.

Osorio, Betty. "María Teresa Ramírez Nieva: reconstrucción de la memoria africana del litoral Pacífico colombiano". Poemas y cantos: antología crítica de autoras afrodescendientes de América Latina. Biblioteca Digital de la Biblioteca Nacional de Colombia. Web. $<$ https://bibliotecanacional.gov.co/es-co/colecciones/biblioteca-digital/poemas-ycantos/Paginas/00-home.html>

Pacheco, Carlos. "Sobre la construcción de lo rural y lo oral en la literatura hispanoamericana". Revista de crítica literaria latinoamericana. 21.42. 1995: 57-71. Digital.

Ramírez, María Teresa. La noche de mi piel. Roldanillo: Ediciones Embalaje del Museo Rayo, 1988. Impreso.

Valencia, María Elcina. Pentagrama de pasión. Bogotá: Editorial Códice, 2010. Impreso.

Valero, Silvia. "¿De qué hablamos cuando hablamos de" literatura afrocolombiana"? o los riesgos de las categorizaciones". Estudios de Literatura Colombiana. 32. 2013: 15-37. Digital. 